\title{
Optimization of Value Added Cookies Prepared with Blends of Pearl Millet Flour and Freeze Dried Ripe Green Banana Flour using Response Surface Methodology
}

\author{
S. Alamelu Mangai' and V. Divyabharathi ${ }^{2}$ \\ 'Assistant Professor, PG and Research Department of Home Science, \\ Bharathidasan Govt. College for Women (Autonomous), Puducherry-03, India; mangaiguru@yahoo.co.in \\ ${ }^{2}$ Research Scholar, PG and Research Department of Home Science, \\ Bharathidasan Govt. College for Women (Autonomous), Puducherry-03, India
}

\begin{abstract}
The future foods for better health and nutrition security are millets. Literature review evidences that regular consumption of green banana flour can be beneficial for humans. Hence an attempt was made with an objective to optimize the Pearl Millet Flour (PMF) with blends of Freeze Dried Ripe Green Banana Flour (FDRGBF) in order to obtain the acceptability level of cookies using response surface methodology. The result shows that, optimum solution by numerical optimization was 90 percent of PMF and 10 percent of FRGBF to get maximum quality and acceptability of cookies. Thus value added cookies can be developed at low cost to improve the health and to enhance the nutritional quality.
\end{abstract}

Keywords: Freeze Dried Ripe Green Banana, Pearl Millet, Response Surface Methodology

\section{Introduction}

Millets have recently gained popularity due to its nutritious benefits and gluten- free status [1]. The future foods for better health and nutrition security are millets. One among the major millet is Pearl millet (Pennisetumglaucum) popularly called kambu in Tamil. Currently India is the largest producer of pearl millet and it has potential for future human use [2]. Pearl millet is rich in protein, iron, calcium, phosphorus, zinc, dietary fiber and high level of fat [3].

Banana is the second largest produced fruit after citrus and contributes about 16 per cent of world's total fruits production. Among the banana, green banana (Musa sapientum) pachai vazhaipazham in tamil is one of the variety produced in India. It provides fiber, vitamins and minerals, phenolic acids, and resistant starch which are important for human health. Being highly perishable, a new economic strategy is to utilize green banana in the form of flour so that it can be used in food industry. The use of ripe green banana flour in the production of gluten free food could help improving nutritional, sensorial and technological quality of the products, as well as providing more accessible products-with a lower cost- to the intended public [4].

RSM (Response surface methodology) is a statistical tool used to estimate quantitative data from various experimental designs to determine and simultaneously solve the multivariate equations [5]. It is an empirical modeling system for developing, improving, and optimizing of complex process [6]. Hence with this background a study was undertaken with the objective to determine the optimum level of pearl millet flour that can be blended with ripe green banana flour in the preparation of cookies using RSM. 


\section{Materials and Methods}

\subsection{Experimental Design}

A Central Composite Rotatable Design (CCRD) of RSM was employed for data collection by two-level-two factors of variable combinations. Numerical optimization technique of the Design-Expert 8 (Stat-Ease Inc, Minneapolis, USA) was used for the simultaneous optimization of the multiple responses.

\subsection{Single Factor Experiment}

To study the overall acceptability of cookies the ingredients such as the pearl millet flour and ripe green banana flour were chosen. Factors investigated in the experiments were pearl millet flour content $(95,90,85,80,75$ and 70g), ripe green banana flour $(5,10,15,20,25$ and 30g).These formulations are shown as trial I to trial VI in the Table 1. Using single factor experiment, minimum and maximum range of pearl millet flour and ripe green banana flour proportion was noted.

\subsection{Optimization of Ingredient by RSM}

CCRD was applied for the present study to determine the optimum levels of the ingredients for the value added cookies. Two independent variables PMF and FDRGBF were chosen for central composite design.
The two-level-two-factor experimental design was adopted. The design includes 13 experimental runs. The response variables were texture $\left(\mathrm{Y}_{1}\right)$ and overall acceptability $\left(\mathrm{Y}_{2}\right) . \mathrm{X}_{1}$ is the code for $\operatorname{PMF}(-1.414,-1,0,+1$, $+1.414)$ and $X_{2}$ is the code for $\operatorname{RGBF}(-1.414,-1,0,+1$, $+1.414)$. The coding of the independent variables is presented in Table 2 and the experimental design in Table 3. Regression analysis and ANOVA were conducted, and the quadratic equations took the form of:

$$
\mathrm{Y}=\mathrm{b}_{0}+\mathrm{b}_{1} \mathrm{X}_{1}+\mathrm{b}_{2} \mathrm{X}_{2}+\mathrm{b}_{12} \mathrm{X}_{1} \mathrm{X}_{2}+\mathrm{b}_{11} \mathrm{X}_{1}^{2}+\mathrm{b}_{22} \mathrm{X}_{2}^{2}
$$

where $\mathrm{Y}$ denotes measured response associated with each factor level combination; $b_{0}$ is an intercept; $b_{1}$ to $b_{22}$ are the regression coefficients; $\mathrm{X}_{1}$ and $\mathrm{X}_{2}$ are the independent variables.

\section{Results and Discussion}

\subsection{Optimization of Ingredients by using Response Surface Methodology}

A CCRD of RSM was used to collect the data by twolevel-two-factors of variable combinations. The experiment was performed using combination of variables for the two response functions, texture and overall acceptability. The central points of the response of control factors

Table 1. Variations in single factor experiment

\begin{tabular}{|l|c|c|c|c|c|c|c|}
\hline \multirow{2}{*}{ Ingredients (g) } & \multirow{2}{*}{ Control } & \multicolumn{7}{|c|}{ Trials } \\
\cline { 3 - 8 } & & I & II & III & IV & V & VI \\
\hline Pearl millet flour & 100 & 95 & 90 & 85 & 80 & 75 & 70 \\
\hline Ripe green Banana flour & - & 5 & 10 & 15 & 20 & 25 & 30 \\
\hline Unsalted Butter & 40 & 40 & 40 & 40 & 40 & 40 & 40 \\
\hline Powdered Sugar & 40 & 40 & 40 & 40 & 40 & 40 & 40 \\
\hline Baking powder & 0.5 & 0.5 & 0.5 & 0.5 & 0.5 & 0.5 & 0.5 \\
\hline
\end{tabular}

Table 2. Ingredient variables and codes

\begin{tabular}{|l|c|c|}
\hline \multirow{2}{*}{ Codes } & \multicolumn{2}{|c|}{ Independent Variables } \\
\cline { 2 - 3 } & $\mathbf{X}_{\mathbf{1}}(\mathbf{g})$ & $\mathbf{X}_{2}(\mathbf{g})$ \\
\hline-1.414 & 82.92 & 2.92 \\
\hline-1 & 85 & 5 \\
\hline 0 & 90 & 10 \\
\hline+1 & 95 & 15 \\
\hline+1.414 & 97.07 & 17.07 \\
\hline
\end{tabular}

$\mathrm{X}_{1:}$ Pearl millet flour, $\mathrm{X}_{2}$ : Ripe green banana flour 
Table 3. Experimental design of response surface analysis

\begin{tabular}{|l|c|c|c|c|}
\hline \multirow{2}{*}{ Run } & \multicolumn{2}{|c|}{$\begin{array}{c}\text { Independent } \\
\text { Variables }\end{array}$} & \multicolumn{2}{c|}{ Responses } \\
\cline { 2 - 5 } & $\mathrm{X}_{1}$ & $\mathrm{X}_{2}$ & $\mathrm{Y}_{1}$ & $\mathrm{Y}_{2}$ \\
\hline 1 & 85 & 15 & 7 & 7.1 \\
\hline 2 & 85 & 5 & 7.2 & 7.3 \\
\hline 3 & 95 & 15 & 7.3 & 7.3 \\
\hline 4 & 90 & 10 & 8 & 9 \\
\hline 5 & 90 & 10 & 8.2 & 8.6 \\
\hline 6 & 90 & 10 & 9 & 8 \\
\hline 7 & 90 & 10 & 8.5 & 8.6 \\
\hline 8 & 95 & 5 & 8.1 & 8 \\
\hline 9 & 90 & 17.0711 & 7.4 & 7.2 \\
\hline 10 & 90 & 2.92893 & 7.3 & 7.2 \\
\hline 11 & 97.0711 & 10 & 7.2 & 7.3 \\
\hline 12 & 90 & 10 & 8.2 & 8.5 \\
\hline 13 & 82.9289 & 10 & 7.4 & 7.3 \\
\hline
\end{tabular}

$\mathrm{X}_{1}$ - Pearl millet flour; $\mathrm{X}_{2}$ - Ripe green banana flour

$\mathrm{Y}_{1}$-Texture; $\mathrm{Y}_{2}$ - Overall acceptability

showed the best results according to the sensorial scale used, qualifying the sensory attributes. Therefore the centre point was taken as a standardized product for the further analysis (Stat-Ease Inc, Minnepolis, USA). ANOVA was performed to evaluate the adequacy of the generated mathematical model as shown in Table 4.

\subsubsection{Texture $\left(Y_{1}\right)$}

Koocheki et al. [7] mentioned that coefficients of determination $\left(\mathrm{R}^{2}\right)$ and adj- $\mathrm{R}^{2}$ indicate the adequacy of the model, where $R^{2}$ is more than 75 percent to ensure the suitability of the model. The p-value was significant. From the Table 4, the regression analysis showed that the co-efficient of determination $\left(\mathrm{R}^{2}=0.7668\right)$ was satisfactory to validate the significance of the model. Furthermore, results of the error analysis indicated that the lack of fit was not significant with $\mathrm{p}$-value of 0.4843 ( $\mathrm{p}>0.05)$. The linear, interaction of the pearl millet flour and ripe green banana flour has significant effect while the quadratic term has no significant effects. The regression equation for the response functions in the coded factors is:

$$
\begin{aligned}
& \mathrm{Y}_{1}=8.38+0.11 \mathrm{X}_{1}-0.11 \mathrm{X}_{2}-0.12 \mathrm{X}_{1} \mathrm{X}_{2}-0.52 \mathrm{X}_{1}^{2}- \\
& 0.50 \mathrm{X}_{2}^{2}
\end{aligned}
$$

Moreover the adequacy of the quadratic model was convinced with the non significant effect of lack of fits.
Table 4. Condensed anova table for texture $\left(\mathrm{y}_{1}\right)$ and overall acceptability $\left(\mathrm{y}_{2}\right)$

\begin{tabular}{|l|c|c|c|c|}
\hline \multirow{2}{*}{$\begin{array}{l}\text { Vource of } \\
\text { Variations }\end{array}$} & \multicolumn{2}{|c|}{$\mathrm{Y}_{1}$} & \multicolumn{2}{c|}{$\mathrm{Y}_{2}$} \\
\cline { 2 - 5 } & $\begin{array}{c}\text { Sum of } \\
\text { square }\end{array}$ & $\mathrm{p}$-value & $\begin{array}{c}\text { Sum of } \\
\text { square }\end{array}$ & p-value \\
\hline Models & 3.48 & 0.0352 & 4.72 & 0.0069 \\
\hline $\mathrm{X}_{1}$ & 0.11 & 0.4316 & 0.10 & 0.3710 \\
\hline $\mathrm{X}_{2}$ & 0.012 & 0.4603 & 0.10 & 0.3710 \\
\hline $\mathrm{X}_{1} \mathrm{X}_{2}$ & 0.090 & 0.4654 & 0.062 & 0.4771 \\
\hline $\mathrm{X}_{12}$ & 1.89 & 0.0095 & 2.31 & 0.0026 \\
\hline $\mathrm{X}_{22}$ & 1.71 & 0.0119 & 2.73 & 0.0016 \\
\hline Lack of fit & 0.45 & 0.4843 & 0.26 & 0.6055 \\
\hline $\mathrm{R}_{2}$ & \multicolumn{2}{|c|}{0.7668} & \multicolumn{2}{c|}{0.8590} \\
\hline Adj $\mathrm{R}_{2}$ & \multicolumn{3}{|c|}{0.6002} & \multicolumn{2}{c|}{0.7582} \\
\hline
\end{tabular}

Figure 1 showed that the significant quadratic effect of the PDPMF and FDRGBF increased with the increase in the PDPMF and FDRGBF proportion.

\subsubsection{Overall Acceptability $\left(Y_{2}\right)$}

From the ANOVA table regression analysis $\mathrm{R}^{2}$ value of the RGBF incorporated cookies was 0.8590 for the regression model predicting the overall acceptability which shows 85 percent variability in the data was satisfactory to validate the significance of the model. Furthermore, results of the error analysis showed insignificant lack of fit with $\mathrm{p}$ - value of 0.6055 ( $\mathrm{p}>0.55)$. The linear, interaction and quadratic term of the PMF and RGBF content had no significant levels. The regression equation for the response functions in the coded factors is:

$$
\underset{1.63 \mathrm{X}_{2}}{\mathrm{Y}_{2}}=8.54+0.11 \mathrm{X}_{1}-0.11 \mathrm{X}_{2}-0.12 \mathrm{X}_{1} \mathrm{X}_{2}-0.58 \mathrm{X}_{1}^{2}-
$$

The response surface of overall acceptability of the Figure 2 shows the significant quadratic effect of the PDPMF and FDRGBF also increased with increase in RGBF content at certain stage and the overall acceptability slightly decreased at certain range due to the increased concentration of the FDRGBF.

\subsection{Standardization Formula of Optimized Cookies}

The final optimized proportion of cookies is given in Table 5 


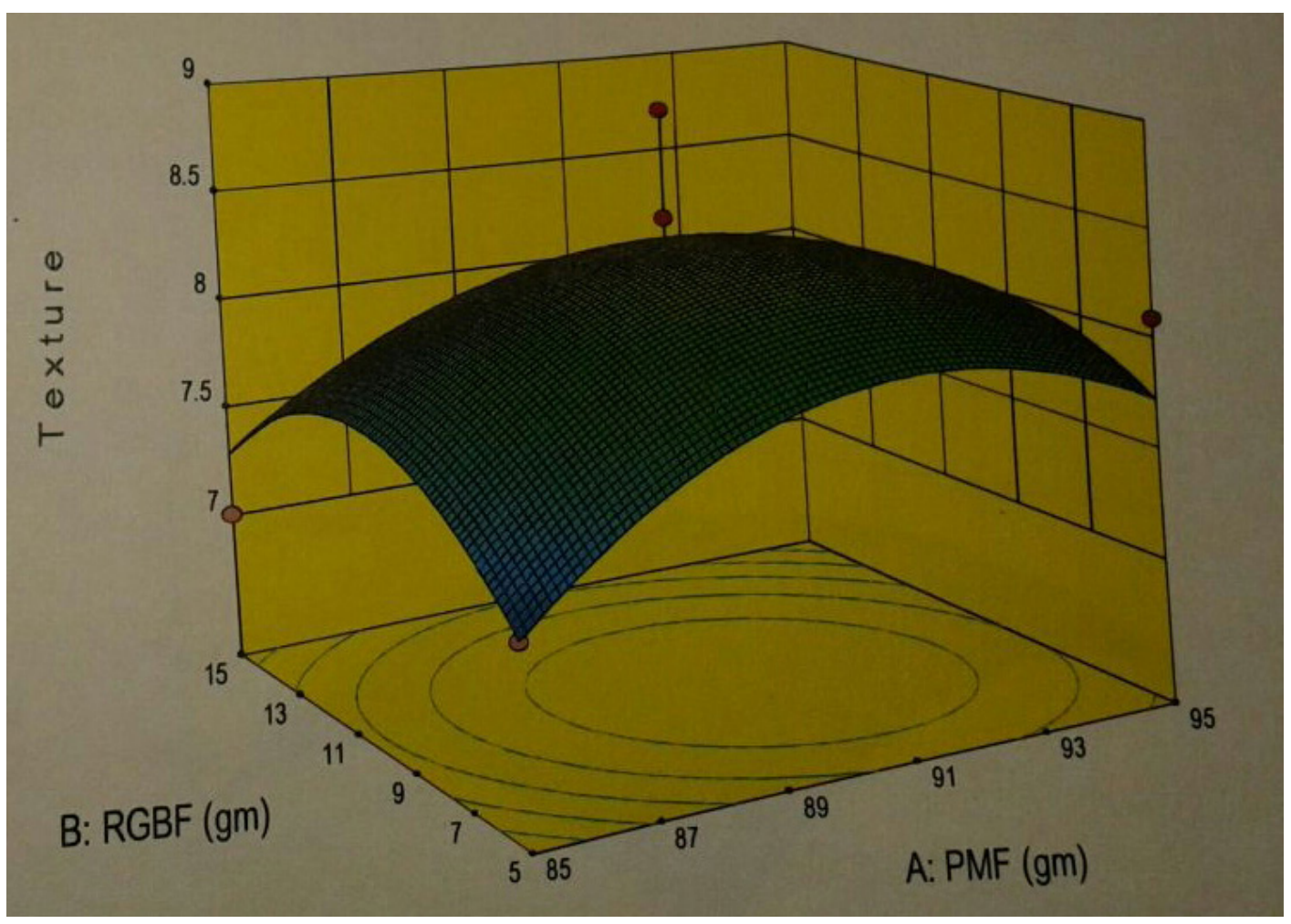

Figure 1. Response surface of texture of cookies.

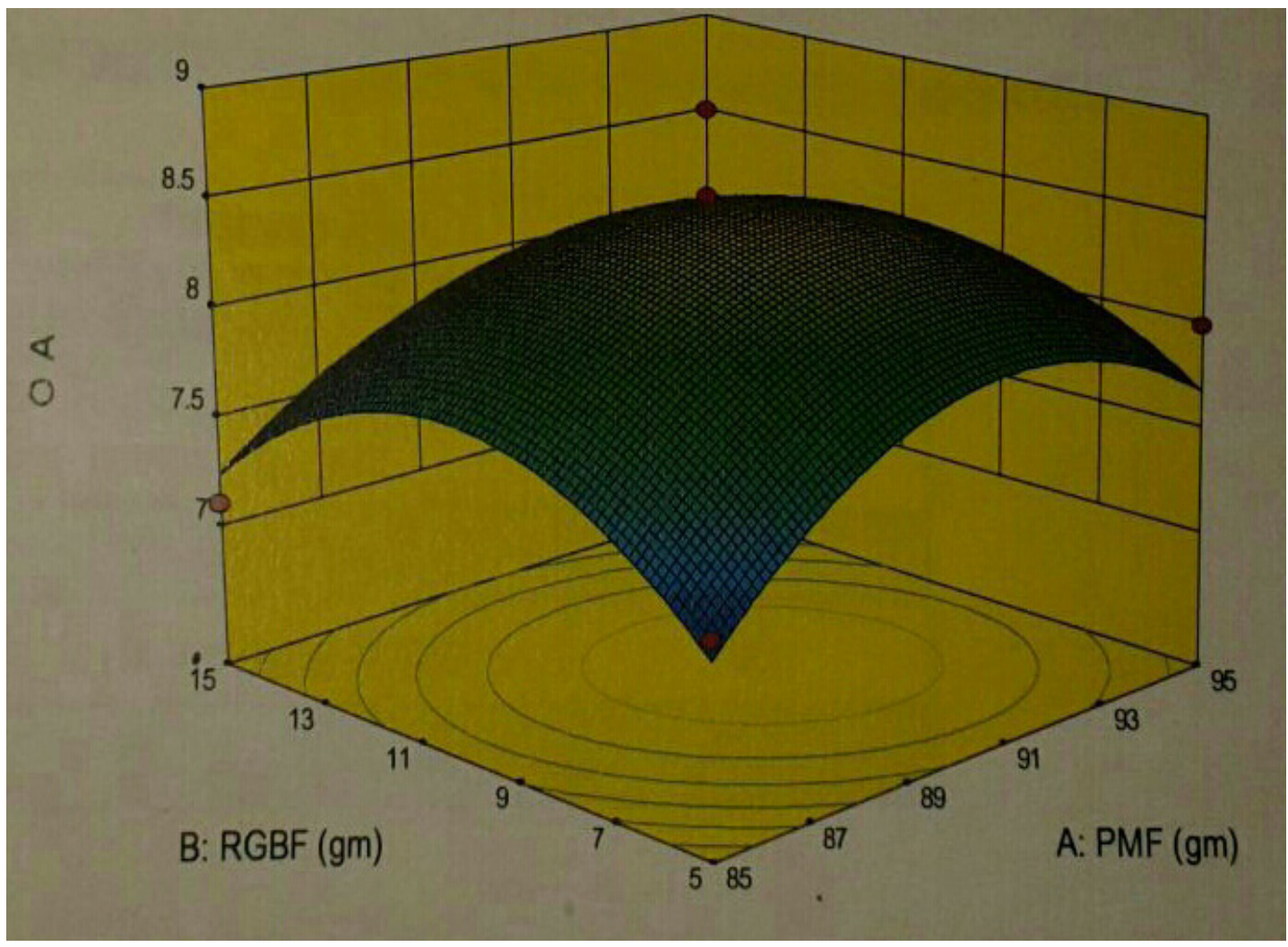

Figure 2. Response surface of overall acceptability of cookies. 
Table 5. Standardized formula ofoptimized cookies

\begin{tabular}{|l|c|}
\hline Ingredients & Quantity (g) \\
\hline Pearl millet flour & 90 \\
\hline Ripe green banana flour & 10 \\
\hline Unsalted butter & 40 \\
\hline Powdered sugar & 40 \\
\hline Baking powder & 0.5 \\
\hline
\end{tabular}

From the optimization it is inferred that $90 \mathrm{~g}$ pearl millet flour with $10 \mathrm{~g}$ ripe green banana flour along with other ingredients such as unsalted butter, powdered sugar and baking powder was the best proportion with respect to texture and overall acceptability. Thus this optimized formula can be utilized for production of pearl millet cookies in large quantities.

\section{Conclusion}

RSM was effective in optimizing the formulation of value added cookies with the ingredients at 85 percent to 95 percent levels Pearl Millet Flour (PMF) and 5 percent to 15 percent Freeze Dried Ripe Green Banana Flour (FDRGBF). The optimum solution was 90 per cent of PMF and 10 percent of FRGBF to get maximum quality and acceptability of cookies. So it was concluded that
RSM would be used effectively to optimize the level of PMF and FDRGBF of value added cookies.

\section{References}

1. Available: http://chetday.com/millet.html

2. Krishnan P. G., and Abdelghafor R. F. "Quality of bread from composite flour of sorghum and hard white winter wheat". Journal of Food Science and Technology, vol. 3(1), p. 9-15, 2011.

3. Fasasi O. S. "Proximate, Anti-nutritional factors and functional properties of processed pear millet", Journal of Food Technology, vol. 7, p. 92-97, 2009.

4. De Gouveia P. F., and Zandonadi R. P. "Green banana: new alternative for gluten-free products", Agro FOOD Industry Hi Tech, vol. 24(3), p. 49-52, 2013.

5. Box G. E. P., and Wilson K. B. "On the experimental attainment of optimum conditions", Journal of Royal Statistics Society, Series B, vol. 13(1), p. 1-45, 1951.

6. Manohar B., and Divakar S. "Applications of surface plots and statistical design to selected lipasecatalyzed esterification reactions", Process Biochem, vol. 39, p. 847-853, 2004.

7. Koocheki A. R. T., Seyed M. A. Response surface methodology for optimization of extraction yield, viscosity, hue and emulsion stability of mucilage extracted from lepidium perfoliatum seeds. Department of Food Science and Technology, Ferdowsi University of Mashhad (FUM), PO Box 91775-1163, 2009. 